\title{
Health-related quality of life, visual function and treatment satisfaction following intravitreal dexamethasone implant for diabetic macular edema
}

This article was published in the following Dove Press journal:

Patient Preference and Adherence

17 March 2017

Number of times this article has been viewed

\author{
Jayashree Ramu' \\ Irini Chatziralli' \\ Yit Yang ${ }^{2}$ \\ Geeta Menon ${ }^{3}$ \\ Clare Bailey ${ }^{4}$ \\ Michael Eckstein ${ }^{5}$ \\ Phil Hykin' \\ Sobha Sivaprasad'
}

On behalf of the OZDRY

Study Group

'NIHR Moorfields Biomedical Research Centre, London, ${ }^{2}$ The Royal Wolverhampton Hospitals NHS Trust, Wolverhampton, ${ }^{3}$ Frimley Health NHS Foundation Trust, Surrey, ${ }^{4}$ Bristol Eye Hospital, Bristol, ${ }^{5}$ Brighton and Sussex University Hospital, Brighton, UK
Correspondence: Sobha Sivaprasad NIHR Moorfields Biomedical Research Centre, 162 City Road, ECIV 2PD,

London, UK

Tel +442075662039

Fax +44 2075662472

Email senswathi@aol.com
Purpose: The aim of this study was to explore and describe quantitatively patient-reported outcome measures (PROMs), ie, health-related quality of life (QoL), visual function and treatment satisfaction, in patients with diabetic macular edema (DME) receiving two different regimens of Ozurdex (intravitreal dexamethasone implant).

Methods: In this multicenter, prospective study, 100 patients with center-involving refractory DME were randomized 1:1 to either five monthly fixed dosing or optical coherence tomography (OCT)-guided pro re nata $(\mathrm{PRN})$ regimen of dexamethasone intravitreal implant therapy. The primary outcome was the difference between arms in change in PROMs and health-related QoL from baseline to 12 months, as measured by the Retinopathy-Dependent Quality of Life (RetDQoL) questionnaire, Visual Function Questionnaire-25 (VFQ-25) and Retinopathy Treatment Satisfaction Questionnaire (RetTSQ).

Results: There was no statistically significant difference in the RetDQoL score and VFQ-25 score at month 12 compared to those at baseline, whereas the total mean RetTSQ score increased significantly at the exit visit. The two treatment arms did not differ significantly regarding the change in PROMs and health-related QoL questionnaires. Logistic regression analysis showed that visual acuity (VA) of $\geq 55$ letters, central foveal thickness $<300 \mu \mathrm{m}$ and macular volume $<9.2 \mathrm{~mm}^{3}$ at the exit visit (month 12) predicted a higher change in RetTSQ.

Conclusion: This study showed that there is a statistically significant improvement in treatment satisfaction, as measured by RetTSQ, in patients with DME treated with dexamethasone intravitreal implant, independent of the dose regimen, namely, fixed or PRN. However, it should be noted that the clinically meaningful change could not be assessed accurately, since no thresholds for clinically meaningful change currently exist for the RetTSQ. On the other hand, there was no significant change in health-related QoL, as measured using VFQ-25 and RetDQoL. Factors affecting the patients' treatment satisfaction were the final VA, the central foveal thickness and the macular volume.

Keywords: VFQ-25, RetTSQ, RetDQoL, Ozurdex, PRN, treat-and-extent, treatment

\section{Introduction}

Diabetic retinopathy (DR) is one of the most common complications of diabetes mellitus and is considered to be the leading cause of visual impairment among adults $<45$ years old in the industrialized world. ${ }^{1,2}$ Diabetic macular edema (DME) is a sight-threatening complication of DR, and its prevalence has been estimated currently to be $\sim 6.8 \%$, ranging from $3 \%$ in people with newly diagnosed diabetes to $28 \%$ in the population with diabetes for 20 years..$^{2,3}$ Macular laser photocoagulation was the gold standard for the treatment of DME before the advent of anti-vascular endothelial 
growth factor (anti-VEGF) agents. ${ }^{4}$ Although macular laser decreased the risk of visual loss by $50 \%$, only $<4 \%$ of patients had improved visual acuity (VA) based on 15-letter gain after 3 years of laser therapy in the Early Treatment of Diabetic Retinopathy Study (ETDRS). ${ }^{4}$

Currently, in the UK, anti-VEGF agents, such as ranibizumab and aflibercept, are the first-line treatment option for center-involving DME, ie, DME involving the central macula with central subfield thickness (CST) $\geq 400 \mu \mathrm{m}$.,6 Although most recent studies have shown that as many as $40 \%$ of treated patients can achieve significant VA gains with anti-VEGF agents, there is also a significant proportion of patients who show poor or limited response to antiVEGF treatment. ${ }^{7,8}$ Therefore, intravitreal steroids, such as dexamethasone drug delivery system (Ozurdex [intravitreal dexamethasone implant]; Allergan Inc., Irvine, CA, USA), have been approved for the treatment of chronic DME, which has not responded to anti-VEGF therapy. ${ }^{9,10}$ Various studies evaluated different dosing regimens for dexamethasone intravitreal implant, but there is a great deal of uncertainty on the optimal dosing. ${ }^{11-14}$ Repeated administration of dexamethasone intravitreal implant is associated with elevated intraocular pressure (IOP) and cataract formation. ${ }^{11,15} \mathrm{We}$ recently conducted the OZDRY study to compare two dosing regimens of dexamethasone intravitreal implant for chronic DME in terms of the conventional functional and anatomical outcomes of VA and retinal thickness and also to use standard questionnaire tools to explore and describe quantitatively patient-reported outcome measures (PROMs), which are infrequently reported from registration studies. The VA and retinal thickness data have been reported in a previous publication. ${ }^{16}$ In this second report from the OZDRY study, we describe the effect of two different regimens of dexamethasone intravitreal implant therapy for DME on PROMs and some baseline predictors of changes in PROMs using specific questionnaires, ie, the Visual Function Questionnaire-25 (VFQ-25), the Retinopathy-Dependent Quality of Life (RetDQoL) questionnaire and the Retinopathy Treatment Satisfaction Questionnaire (RetTSQ).

\section{Methods}

\section{Study design}

The OZDRY study is a multicenter, prospective, noninferiority, randomized, 12-month study conducted across five sites in the UK. The study aimed to compare the efficacy of five monthly fixed dosing with optical coherence tomography (OCT)-guided pro re nata (PRN) dosing of dexamethasone intravitreal implant in patients with refractory
DME for a period of 12 months. In this subanalysis of the OZDRY study, we evaluated the PROMs in patients treated with dexamethasone intravitreal implant for refractory DME. The study was registered at www.ClinicalTrials.gov/ NCT01892163. The study protocol was approved by the UK Collaborative Research Ethics Committee (12/LO/1534). The principles of Good Clinical Practice were adhered throughout in accordance with the Declaration of Helsinki. Written informed consent was obtained from all participants.

\section{Study population}

A total of 100 patients aged $\geq 18$ years with type 1 or type 2 diabetes and DME were included in the study. The key eligibility criteria for the study eye were as follows: 1) bestcorrected ETDRS VA between 34 and 73 letters (20/20020/40 Snellen) and 2) CST of $\geq 300 \mu \mathrm{m}$ due to DME despite previous treatment. The exclusion criteria included: 1) macular ischemia defined as a foveal avascular zone of $\geq 1,000 \mu \mathrm{m}$ in diameter on fluorescein angiography (performed at baseline using Spectralis HRA+OCT [Heidelberg, Germany]); 2) previous treatment for DME with macular laser within the prior 3 months, intravitreal steroids in the past 6 months or anti-VEGF therapy in the last 1 month; 3) substantial cataract that, in the opinion of the investigator, was likely to decrease the VA by three or more lines; 4) active proliferative DR requiring treatment at screening; 5) vitrectomized eyes; 6) diagnosis of glaucoma that, in the opinion of the glaucoma specialist, was at high risk of progression or ocular hypertension requiring at least one topical medication and 7) coexisting disease affecting the VA of the study eye.

One eye was selected and treated as the study eye. If both eyes were eligible, the eye with the better VA at screening was selected for treatment, unless the patient preferred otherwise.

\section{Questionnaires}

To assess the PROMs in patients treated with dexamethasone intravitreal implant for refractory DME, as part of the OZDRY study, ${ }^{16}$ the following questionnaires were administered at screening and at the exit visit (month 12), prior to any intervention/treatment that may affect the patients' response. Higher scores in these questionnaires at the exit visit compared to those at screening indicated better quality of life (QoL) and increased satisfaction.

\section{National Eye Institute VFQ-25 (NEIVFQ-25)}

The NEI VFQ-25 is a questionnaire intended to measure visual function and QoL. It measures the following 
vision-dependent subscales: general vision $(\mathrm{GV})$, ocular pain (OP), near activities (NA), distance activities (DA), visionspecific social functioning (VSSF), vision-specific mental health (VSMH), vision-specific role difficulties (VSRD), vision-specific dependency (VSD), driving (D), color vision $(\mathrm{CV})$ and peripheral vision (PV) as well as one general health (GH) subscale. The original response of each item is coded as per the NEI VFQ-25 scoring system, ranging from 0 to 100. A score of 0 indicates the worst possible score, and a score of 100 indicates the best possible score. The subscales were recoded and scored, as appropriate. ${ }^{17,18}$

\section{RetDQoL}

RetDQoL is a questionnaire designed to measure individualized QoL in people with DR. It consists of two overview items and 26 domain-specific items. For the overview item I (present QoL), participants are asked to complete the statement "In general, my present quality of life is:" using a 7-point scale from "excellent," scored as 3, through "neither good nor bad," scored as 0 , to "extremely bad," scored as -3 . For the overview item II (retinopathy-specific QoL), participants are asked how QoL is affected by diabetic eye problems: "If I did not have diabetic eye problems, my quality of life would be:" with the response options: "very much better" (scored-3), "much better" (scored-2), "better" (scored-1), "the same" (scored 0) and "worse" (scored 1).

For the domain-specific items, the participant indicates whether items are applicable or not to them, and for the applicable ones, they rate the impact of diabetic eye problems on each aspect of life (first part) and then the importance of each aspect of life to the individual's QoL (second part). The impact items range from "very much better" (scored -3 ), "much better" (scored -2 ), "little better" (scored -1 ), "same" (scored 0) and "worse" (scored 1). The importance ratings range from "very important" (scored 3), "important" (scored 2), "somewhat important" (scored 1) and "not at all important" (scored 0). The impact and importance ratings for each applicable item are then multiplied to obtain a weighted impact score with a range from -9 to 3 . A more negative weight impact score indicates a more negative impact of DR on QoL; a positive weight impact score would indicate a positive impact of DR on QoL. A total score, the average weight impact (AWI) score, can be obtained by summing the weighted impact scores of all applicable domain-specific items and dividing the result by the number of applicable domains. In our study, the RetDQoL options were numbered starting from 1 for convenience of administration and converted to the respective scores for analysis.

The RetDQoL finishes with an open-ended question that asks whether diabetic eye problems affect QoL in any way not already covered by the questionnaire. ${ }^{19}$

\section{RetTSQ}

This questionnaire consists of 13 questions asking participants to rate various aspects of treatment on a scale of $0-6$, with 0 being least favorable to 6 being highly favorable, generating a range of possible total scores from 0 to 78 . The last item is a free text option, which asks about any other aspects not covered in the previous 13 questions. The RetTSQ provides two subscale scores: seven subscales providing positive aspects (range 0-42) that include items 1, 2, 8, 9, 11, 12 and 13 and six subscales with negative aspects (range 0-36) that include items 3, 4, 5, 6, 7 and 10. Higher scores for the total scale and the subscales represent increased satisfaction with treatment. The various subscales and the scoring are shown in Table $1 .^{20}$

Table I RetTSQ subscales and scoring

\begin{tabular}{llll}
\hline No & RetTSQ question description & Subscale & Comments \\
\hline I & Current satisfaction & Positive & \\
2 & Treatment working well & Positive & \\
3 & Side effects & Negative & \\
4 & Discomfort/pain & Negative & \\
5 & Unpleasant & Negative & Scores from 0 to 6, being least favorable to high favorable. \\
6 & Difficult & Negative & Possible total scores range from 0 to 78 \\
7 & Apprehensive & Negative & Subscales: positive (7 items; possible positive scores range from 0 to 42) \\
8 & Influence & Positive & and negative (6 items; possible negative scores range from 0 to 36) \\
9 & Safety & Positive & \\
10 & Time consuming & Negative & \\
II & Information & Positive & \\
12 & Encourage others & Positive & \\
I3 & Continue/repeat & Positive & \\
I4 & Any other features & & \\
\hline
\end{tabular}

Abbreviation: RetTSQ, Retinopathy Treatment Satisfaction Questionnaire. 


\section{Statistical analysis}

Quantitative measures of PROMs at baseline and month 12 were described using the descriptive statistics of mean score of each questionnaire. Comparative analyses between the trial arms were performed using the Mann-Whitney $U$ test for quantitative variables and the chi-squared test or Fisher's exact test, as appropriate, for qualitative variables. Multivariate logistic regression analysis was performed to evaluate the factors, which predict the change in the RetTSQ score. A $P$-value of $<0.05$ was considered significant. No multiplicity corrections were made, since the basic comparison was between baseline and month 12 for all parameters. All analyses were performed with SPSS 22.0 (SPSS Inc., Chicago, IL, USA).

\section{Results}

A total of 100 patients with refractory DME were enrolled into the study, of whom 95 patients who had completed the questionnaires at baseline and the exit visit were included in the analysis. Of note, there were no missing data, as all PROMs' questionnaires were completed at both baseline and the exit visit. The mean age at baseline was $64.5 \pm 10.7$ years. A total of $74.7 \%$ of patients were males and $25.3 \%$ were females. A total of $73.7 \%$ of patients were phakic and $26.3 \%$ were pseudophakic. The mean duration of diabetes was $16.3 \pm 10.3$ years. The mean HbA1c was $7.9 \% \pm 1.4 \%$. In all, $52.6 \%$ of patients received insulin and $47.4 \%$ oral tablets for the treatment of diabetes. The mean duration of DME was $<3$ years in $50.5 \%$ of patients and $\geq 3$ years in $49.5 \%$ of patients. Regarding DR severity, $32.6 \%$ of patients had mild DR, $38.9 \%$ moderate DR, $11.6 \%$ severe DR and $16.8 \%$ treated proliferative DR. In addition, five patients (5.3\%) had only previous intravitreal anti-VEGF treatment and $49.5 \%$ of patients had only previous macular laser treatment, whereas $45.2 \%$ of patients had received a combination of laser with either anti-VEGF or steroids. Patients were randomized to receive dexamethasone intravitreal implant in a fixed-dose regimen (50.5\%) or PRN (49.5\%).

At baseline, the mean best-corrected visual acuity (BCVA) was $59.3 \pm 9.3$ letters, the mean CST was $466.5 \pm 115.2 \mu \mathrm{m}$ and the mean macular volume was $10.2 \pm 2.2 \mathrm{~mm}^{2}$. The mean change in BCVA was $+1.48 \pm 14.8$ in the fixed arm vs $-0.17 \pm 13.1$ in the PRN arm. The mean number of dexamethasone intravitreal implant injections was $2.86 \pm 0.48$ in the fixed arm and $2.60 \pm 0.70$ in the PRN arm with a median of three injections in both arms.

\section{QoL results}

Table 2 lists the changes in scores of the RetDQoL, NEI VFQ-25 and RetTSQ at the exit visit compared to those
Table 2 Change in questionnaires from baseline to month 12

\begin{tabular}{lllllll}
\hline $\begin{array}{lllll}\text { Questionnaire } \\
\text { score change }\end{array}$ & Overall & & Fixed & & PRN & P-value \\
\cline { 2 - 2 } & Mean \pm SD & & Mean \pm SD & & Mean \pm SD & \\
\hline RetDQoL & $-3.01 \pm 2.37$ & & $-2.95 \pm 2.13$ & & $-3.16 \pm 2.62$ & 0.794 \\
NEI VFQ-25 & $3.39 \pm 14.2$ & & $6.68 \pm 14.7$ & & $0.09 \pm 13.0$ & $\mathbf{0 . 0 5 6}$ \\
RetTSQ & $4.04 \pm 13.72$ & & $4.35 \pm 12.8$ & & $3.72 \pm 14.8$ & 0.861 \\
\hline
\end{tabular}

Note: Bold value denotes borderline significance.

Abbreviations: PRN, pro re nata; RetDQoL, Retinopathy-Dependent Quality of Life; NEI VFQ-25, National Eye Institute Visual Function Questionnaire-25; RetTSQ, Retinopathy Treatment Satisfaction Questionnaire; SD, standard deviation.

at baseline in the whole population and in the two arms separately.

The RetDQoL score at baseline was $-3.07 \pm 2.43$ and did not differ significantly compared to the score at month 12 . The analysis showed a negative change score for the overall population $(-3.01 \pm 2.37)$ and for both arms $(-2.95 \pm 2.13$ and $-3.16 \pm 2.62$ for the fixed arm and PRN arm, respectively, $P=0.794)$, implying that the QoL did not show any improvement for these patients following dexamethasone intravitreal implant therapy. Moreover, domain-specific analysis also did not show any significant change in all domains between the two groups, as shown in Table 3.

The mean NEI VFQ-25 composite score at baseline for the whole study sample was $74.1 \pm 19.9$ and did not differ significantly compared to the score at month 12 (77.2 \pm 18.7$)$. There was a borderline difference in the NEI VFQ-25 composite score change at the exit visit compared to that at baseline between patients who were treated in the fixed arm versus PRN arm (6.68 \pm 14.7 vs $0.09 \pm 13.0$ for the fixed arm and PRN arm, respectively, $P=0.056$ ), as shown in Table 2. Sub-scale analysis between arms showed a statistically significant change for the "DA" $(9.28 \pm 19.2$ vs $-2.17 \pm 18.3$ for the fixed arm and PRN arm, respectively, $P=0.008)$ and "color vision" (7.81 \pm 25.9 vs $-0.53 \pm 11.0$ for the fixed arm and PRN arm, respectively, $P=0.045)$. None of the other subscale scores showed any significance, as shown in Table 4. However, when a subscale analysis was carried out for the score change following dexamethasone intravitreal implant therapy, between the "better seeing eye" (BSE) and "worse seeing eye" (WSE) as the study eye, the "GV" subscale $(-5.71 \pm 18.0$ vs $3.89 \pm 16.7$ for BSE and WSE, respectively, $P=0.036)$ and the "OP" subscale $(-12.5 \pm 21.7$ vs $1.94 \pm 18.3$ for BSE and WSE, respectively, $P=0.007$ ) showed statistically significant change. This implies that patients with the WSE eye showed better improvement and were more satisfied.

The total mean RetTSQ score at baseline was $59.08 \pm 11.20$ and increased significantly to $63.13 \pm 12.25$ at the exit visit $(P=0.01)$. There was no statistically significant difference in 
Table 3 RetDQoL score change between baseline and the exit visit in all domains

\begin{tabular}{|c|c|c|c|c|}
\hline \multirow[t]{2}{*}{ RetDQoL subscales } & \multirow{2}{*}{$\begin{array}{l}\begin{array}{l}\text { All } \\
\text { patients }\end{array} \\
\text { Mean } \pm \text { SD }\end{array}$} & \multirow{2}{*}{$\begin{array}{l}\text { Fixed Ozurdex (dexamethasone } \\
\text { intravitreal implant) } \\
\text { Mean } \pm \text { SD }\end{array}$} & \multirow{2}{*}{$\begin{array}{l}\text { PRN dexamethasone } \\
\text { intravitreal implant } \\
\text { Mean } \pm \text { SD }\end{array}$} & \multirow[t]{2}{*}{$P$-value } \\
\hline & & & & \\
\hline Present QoL & $-0.06 \pm 1.17$ & $0.06 \pm 1.42$ & $-0.19 \pm 0.85$ & 0.288 \\
\hline QoL without diabetes & $-0.06 \pm 1.23$ & $-0.15 \pm 1.43$ & $0.02 \pm 0.99$ & 0.661 \\
\hline Household tasks & $-0.49 \pm 3.30$ & $-0.60 \pm 3.78$ & $-0.38 \pm 2.77$ & 0.757 \\
\hline Personal affairs & $0.00 \pm 3.31$ & $-0.31 \pm 3.66$ & $0.33 \pm 2.91$ & 0.279 \\
\hline Shopping & $-0.37 \pm 2.86$ & $-0.22 \pm 3.16$ & $-0.52 \pm 2.55$ & 0.726 \\
\hline Feelings about the future & $-0.13 \pm 3.13$ & $-0.02 \pm 3.38$ & $-0.23 \pm 2.88$ & 0.875 \\
\hline Anger or regret & $-0.43 \pm 3.27$ & $-0.42 \pm 3.74$ & $-0.43 \pm 2.74$ & 0.997 \\
\hline Work & $-0.70 \pm 2.48$ & $-0.53 \pm 2.83$ & $-0.92 \pm 2.07$ & 0.798 \\
\hline Personal relationship & $-0.49 \pm 3.16$ & $-0.33 \pm 3.34$ & $-0.60 \pm 3.06$ & 0.425 \\
\hline Family life & $-0.11 \pm 3.31$ & $-0.49 \pm 3.42$ & $0.47 \pm 3.17$ & 0.359 \\
\hline Social life & $-0.26 \pm 2.78$ & $-0.38 \pm 2.90$ & $-0.15 \pm 2.67$ & 0.733 \\
\hline Do for others & $-0.33 \pm 3.01$ & $0.02 \pm 3.18$ & $-0.68 \pm 2.81$ & 0.202 \\
\hline Get out and about & $-0.13 \pm 2.75$ & $-0.17 \pm 2.91$ & $-0.09 \pm 2.60$ & 0.910 \\
\hline Holidays & $0.07 \pm 3.18$ & $0.30 \pm 3.81$ & $-0.13 \pm 2.57$ & 0.735 \\
\hline Finance & $-0.13 \pm 2.56$ & $-0.29 \pm 2.58$ & $0.04 \pm 2.55$ & 0.242 \\
\hline People's reaction to me & $-0.18 \pm 2.58$ & $-0.10 \pm 2.86$ & $-0.27 \pm 2.28$ & 0.733 \\
\hline Physical appearance & $-0.03 \pm 2.60$ & $0.02 \pm 2.93$ & $-0.09 \pm 2.24$ & 0.597 \\
\hline Do physically & $-0.32 \pm 2.63$ & $-0.7 \mid \pm 2.78$ & $0.09 \pm 2.43$ & 0.081 \\
\hline Leisure & $0.02 \pm 2.64$ & $-0.17 \pm 2.88$ & $0.21 \pm 2.38$ & 0.495 \\
\hline Self-confidence & $-0.20 \pm 3.19$ & $-0.42 \pm 3.23$ & $0.02 \pm 3.16$ & 0.235 \\
\hline Motivation & $-0.42 \pm 2.88$ & $-0.52 \pm 2.77$ & $-0.32 \pm 3.02$ & 0.925 \\
\hline Independence & $-1.02 \pm 3.06$ & $-1.44 \pm 3.58$ & $-0.66 \pm 2.54$ & 0.366 \\
\hline Mishaps & $-0.21 \pm 2.90$ & $-0.49 \pm 3.06$ & $0.06 \pm 2.75$ & 0.184 \\
\hline Time taken & $-0.56 \pm 2.93$ & $-0.81 \pm 3.02$ & $-0.30 \pm 2.84$ & 0.161 \\
\hline Care for my diabetes & $0.22 \pm 3.39$ & $-0.23 \pm 3.42$ & $0.68 \pm 3.32$ & $0.44 I$ \\
\hline Enjoy nature & $-0.08 \pm 2.53$ & $-0.06 \pm 2.94$ & $-0.11 \pm 2.06$ & 0.747 \\
\hline Composite score & $-3.01 \pm 2.37$ & $-2.95 \pm 2.13$ & $-3.16 \pm 2.62$ & 0.794 \\
\hline
\end{tabular}

Abbreviations: RetDQoL, Retinopathy-Dependent Quality of Life; PRN, pro re nata; QoL, quality of life; SD, standard deviation.

Table 4 NEI VFQ-25 score change between the exit visit and baseline

\begin{tabular}{|c|c|c|c|c|}
\hline \multirow[t]{2}{*}{$\begin{array}{l}\text { NEI VFQ-25 } \\
\text { subscales }\end{array}$} & $\begin{array}{l}\text { All } \\
\text { patients }\end{array}$ & $\begin{array}{l}\text { Fixed Ozurdex (dexamethasone } \\
\text { intravitreal implant) }\end{array}$ & $\begin{array}{l}\text { PRN dexamethasone } \\
\text { intravitreal implant } \\
\end{array}$ & $P$-value \\
\hline & Mean \pm SD & Mean \pm SD & Mean \pm SD & \\
\hline GV & $1.89 \pm 17.3$ & $1.67 \pm 16.9$ & $2.13 \pm 17.8$ & 0.917 \\
\hline NA & $0.6 I \pm 20.2$ & $3.47 \pm 22.7$ & $-2.3| \pm| 7.0$ & 0.362 \\
\hline DA & $3.43 \pm 19.5$ & $9.28 \pm 19.2$ & $-2.17 \pm 18.3$ & 0.008 \\
\hline VSMH & $557 \pm 24.4$ & $5.31 \pm 27.2$ & $5.84 \pm 21.4$ & 0.942 \\
\hline VSRD & $0.27 \pm 27.2$ & $-0.26 \pm 29.1$ & $0.82 \pm 25.3$ & 0.734 \\
\hline VSD & $2.48 \pm 25.5$ & $1.74 \pm 27.2$ & $3.26 \pm 24.0$ & 0.813 \\
\hline VSSF & $3.23 \pm 19.9$ & $6.25 \pm 21.1$ & $0 \pm 18.3$ & 0.142 \\
\hline D & $1.25 \pm 16.2$ & $0 \pm 4.6$ & $1.92 \pm 14.8$ & 0.949 \\
\hline CV & $3.68 \pm 20.3$ & $7.8 I \pm 25.9$ & $-0.53 \pm 11.0$ & 0.045 \\
\hline OP & $-1.33 \pm 19.7$ & $2.60 \pm 19.3$ & $-5.43 \pm 19.5$ & 0.061 \\
\hline PV & $0.79 \pm 27.5$ & $4.69 \pm 27.1$ & $-3.26 \pm 27.7$ & 0.138 \\
\hline $\mathrm{GH}$ & $-1.86 \pm 23.8$ & $1.06 \pm 25.0$ & $-4.79 \pm 22.5$ & 0.917 \\
\hline $\begin{array}{l}\text { Composite score } \\
\text { (minus GH) }\end{array}$ & $3.39 \pm 14.2$ & $6.68 \pm 14.7$ & $0.09 \pm 13.0$ & 0.065 \\
\hline
\end{tabular}

Note: Bold values denote statistical significance.

Abbreviations: NEI VFQ-25, National Eye Institute Visual Function Questionnaire-25; PRN, pro re nata; GV, general vision; NA, near activities; DA, distance activities; VSMH, vision-specific mental health; VSRD, vision-specific role difficulties; VSD, vision-specific dependency; VSSF, vision-specific social functioning; D, driving; CV, color vision; OP, ocular pain; PV, peripheral vision; GH, general health; SD, standard deviation. 
the change of overall RetTSQ score or in each question score between the two treatment arms, as shown in Table 5. The analysis between the BSE and WSE was done for 93 patients, as two patients had similar vision in both eyes at baseline. Although there was a marginal difference in the total and subscale scores between the BSE and WSE at baseline, the mean was almost identical at exit.

The BCVA correlated positively with NEI VFQ-25 at baseline (Spearman's rho $=+0.252, P=0.014$ ) and at the exit visit (Spearman's rho $=+0.319, P=0.004$ ). The NEI VFQ-25 score correlated with the RetDQoL score at baseline (Spearman's rho $=+0.648, P<0.001$ ) and at the exit visit (Spearman's rho $=+0.585, P<0.001$ ). BCVA and macular thickness did not correlate with RetDQoL at any time point.

Logistic regression analysis for factors predicting RetTSQ showed that VA of $\geq 55$ letters, CST $<300 \mu \mathrm{m}$ and macular volume $<9.2 \mathrm{~mm}^{3}$ at the exit visit predicted a higher change in RetTSQ (Table 6). It is worthy to note that baseline VA and CST were not found to affect the RetTSQ change.

\section{Discussion}

Various treatment options are approved for the treatment of DME in the National Health Service (NHS) in the UK. ${ }^{5,6,11,21,22}$ Treatment satisfaction with dexamethasone intravitreal implant has not been formally assessed for this condition. The RetDQoL is the only available validated disease-specific treatment satisfaction questionnaire for DR, ${ }^{19}$ while RetTSQ is a questionnaire specific for retinopathy

Table 5 RetTSQ score change at the exit visit compared to baseline

\begin{tabular}{|c|c|c|c|}
\hline \multirow[t]{2}{*}{ RetTSQ subscales } & \multirow{2}{*}{$\frac{\text { PRN }}{\text { Mean } \pm \text { SD }}$} & \multirow{2}{*}{$\frac{\text { Fixed }}{\text { Mean } \pm \text { SD }}$} & \multirow[t]{2}{*}{$P$-value } \\
\hline & & & \\
\hline Current satisfaction & $0.32 \pm 1.4$ & $0.2 I \pm I .2$ & 0.525 \\
\hline Treatment working well & $0.62 \pm 2.0$ & $0.29 \pm 1.7$ & 0.162 \\
\hline Side effects & $0.15 \pm 2.3$ & $0.77 \pm 2.2$ & 0.140 \\
\hline Discomfort/pain & $0.47 \pm 2.2$ & $0.77 \pm 2.4$ & 0.746 \\
\hline Unpleasant & $-0.19 \pm 2.1$ & $0.19 \pm 2.0$ & 0.686 \\
\hline Difficult & $0.30 \pm 1.9$ & $0.38 \pm 2.0$ & 0.873 \\
\hline Apprehensive & $0.49 \pm 2.4$ & $0.79 \pm 2.3$ & 0.567 \\
\hline Influence & $0.64 \pm 1.8$ & $0.0 \pm 1.0$ & 0.185 \\
\hline Safety & $0.36 \pm 1.6$ & $0.52 \pm 1.1$ & 0.712 \\
\hline Time consuming & $0.62 \pm 1.8$ & $0.38 \pm 1.5$ & 0.374 \\
\hline Information & $-0.02 \pm 1.2$ & $0.06 \pm 1.2$ & 0.993 \\
\hline Encourage others & $-0.04 \pm 1.6$ & $0.12 \pm 1.0$ & 0.529 \\
\hline Continue/repeat & $0.02 \pm 1.8$ & $-0.13 \pm 1.7$ & 0.536 \\
\hline Overall score & $3.72 \pm 14.8$ & $4.35 \pm 12.8$ & 0.861 \\
\hline
\end{tabular}

Abbreviations: RetTSQ, Retinopathy Treatment Satisfaction Questionnaire; PRN, pro re nata; SD, standard deviation.
Table 6 Logistic regression analysis for factors affecting RetTSQ

\begin{tabular}{llll}
\hline $\begin{array}{l}\text { Factors at the exit } \\
\text { visit predicting } \\
\text { change in RetTSQ }\end{array}$ & Category & $\begin{array}{l}\text { Odds ratio } \\
\mathbf{( 9 5 \% ~ C l )}\end{array}$ & P-value \\
\hline BCVA (ETDRS letters) & $\geq 55$ vs $<552$ & $3.55(1.17-10.75)$ & 0.03 \\
CST $(\mu \mathrm{m})$ & $\geq 300$ vs $<300$ & $0.28(0.10-0.78)$ & 0.04 \\
Macular volume $\left(\mathrm{mm}^{3}\right)$ & $<9.2$ vs $\geq 9.2$ & $3.13(1.07-9.17)$ & 0.02 \\
\hline
\end{tabular}

Abbreviations: RetTSQ, Retinopathy Treatment Satisfaction Questionnaire; BCVA, best-corrected visual acuity; ETDRS, Early Treatment of Diabetic Retinopathy Study; CST, central subfield thickness.

treatment satisfaction. ${ }^{20}$ In addition, the NEI VFQ-25 is the most commonly used questionnaire to assess the visionrelated QoL. ${ }^{17,18}$ To our knowledge, this is the first study to use RetTSQ, RetDQoL and NEI VFQ-25 for treatment satisfaction of DME in patients using dexamethasone intravitreal implant.

Our study showed a statistically significant treatment satisfaction with a mean of $\sim 3$ dexamethasone intravitreal implant injections over a year for eyes with persistent DME following previous treatment, including macular laser, intravitreal triamcinolone and anti-VEGF agents. ${ }^{23,24}$ The study highlights treatment satisfaction despite no significant mean change in vision or QoL as measured using NEI VFQ-25 and RetDQoL at the end of 12 months. In addition, patients with WSE presented better improvement in NEI VFQ-25, suggesting that patients with the WSE showed better improvement and were more satisfied. Milne et $\mathrm{a}^{25}$ in a comprehensive review of the literature reported that health-related QoL was improved following interventions for DR, while Okamoto et $\mathrm{al}^{26}$ have found that the improvement may be temporary and did not maintain 3 months after treatment. In our study, there was no significant change in health-related QoL either. These discrepancies between studies could be attributed to the different populations, as well as to the small sample size in some studies, leading to lack of power.

An interesting point that should be taken into account, when interpreting the data of health-related QoL outcomes, is that there could be a difference between the statistically significant and the clinically meaningful results. In fact, whether a statistically significant difference could be found or not, a clinically meaningful change may be defined at different points. In addition, a statistical significance is usually determined by the sample size, while clinical interpretation may be totally different. Suñer et $\mathrm{al}^{27}$ have reported that in patients with neovascular age-related macular degeneration, VFQ-25 was a sensitive measure of vision-related function and that a change of 4-6 points could represent a clinically meaningful 
change. In our study, the mean VFQ-25 composite score was $74.1 \pm 19.9$ at baseline and $77.2 \pm 18.7$ at month 12 for the whole study sample, showing no statistically significant difference and no clinically meaningful change between baseline and the exit visit. Regarding the RetTSQ score, it should be noted that the clinically meaningful change could not be assessed accurately, since no thresholds for clinically meaningful change currently exist for the RetTSQ.

It is worthy to note that the treatment satisfaction was dependent on final VA, macular thickness and macular volume, while baseline VA and macular thickness were not found to affect the RetTSQ change. Therefore, patients' perceived satisfaction was based on their final VA status rather than the gain in vision. This is an important point to note when evaluating the quality of service provision of intravitreal services, since audits of visual outcomes are usually based around the mean change in VA from baseline. This study showed that this standard does not correspond to treatment satisfaction perceived by patients, as patients' satisfaction is governed by the final VA. As a result, new standards of visual outcome might reflect proportions of patients who have the final visual outcome of $\geq 55$ ETDRS letters, as shown in our study.

The study did not show any difference in treatment satisfaction between arms despite better NEI VFQ-25 score in the fixed-arm dosing group. This may be due to the injection frequency, which was almost identical in both arms despite the regimen chosen. Further studies on patient satisfaction when treated in a routine outpatient clinical setting are required to evaluate whether these changes are mirrored in real-life settings.

Intravitreal dexamethasone implant has lesser frequency of administration as compared to anti-VEGF agents for a given span of time. However, dexamethasone intravitreal implant, not without complications, has increased frequency of raised IOP and progression of cataract compared with anti-VEGF agents. ${ }^{11,15,28,29}$ Therefore, the treatment satisfaction noted with dexamethasone intravitreal implant in this study should not be generalized to patients receiving repeated anti-VEGF agents. Similarly, the study results should not be assumed to reflect the satisfaction with fluocinolone implant for DME. Further studies on treatment satisfaction and QoL should be performed with each of these agents and treatment regimens.

A potential limitation of this study was the relatively small sample size. In fact, this study is a supplementary study to the previously published clinical data, comparing fixed and PRN treatment regimens in patients with DME treated with intravitreal dexamethasone implant. Therefore, it should be noted that the sample size may be not sufficient to detect change in PROMs.

\section{Conclusion}

This study showed that there is a statistically significant improvement in treatment satisfaction, as measured by RetTSQ, which increased from 59.08 \pm 11.20 at baseline to $63.13 \pm 12.25$ at month 12 , in patients with DME treated with dexamethasone intravitreal implant, independent of the dose regimen, namely, fixed or PRN. However, there was no significant change in health-related QoL, as measured using NEI VFQ-25 and RetDQoL. Nevertheless, it should be noted that there may be a discrepancy between statistically significant and clinically meaningful change, when interpreting health-related QoL questionnaires, which may be due to the variation in populations and the lack of power in some studies. In our study, factors affecting the patients' treatment satisfaction were the final VA, the CST and the macular volume. Therefore, it is useful to measure PROMs in treatment trials, since they give us a direct measure of how the VA gains from therapy translate into the patients' experience in everyday life.

\section{Acknowledgments}

The research was funded by Allergan Inc. and supported by the National Institute for Health Research (NIHR) Biomedical Research Centre at Moorfields Eye Hospital NHS Foundation Trust, the UCL Institute of Ophthalmology and the NIHR Moorfields Clinical Research Facility. The views expressed are those of the authors and not necessarily those of the NHS, the NIHR or the Department of Health.

\section{Disclosure}

Yit Yang, Geeta Menon, Clare Bailey, Phil Hykin and Sobha Sivaprasad have received travel grants, research grants and speaker fees and attended advisory board meetings of Bayer, Allergan and Novartis. The other authors report no conflicts of interest in this work.

\section{References}

1. Frank RN. Diabetic retinopathy. N Engl J Med. 2004;350(1):48-58.

2. Yau JW, Rogers SL, Kawasaki R, et al. Global prevalence and major risk factors of diabetic retinopathy. Diabetes Care. 2012;35(3): $556-564$.

3. Klein R, Klein BE, Moss SE, Davis MD, DeMets DL. The Wisconsin epidemiologic study of diabetic retinopathy. IV. Diabetic macular edema. Ophthalmology. 1984;91(12):1464-1474.

4. [No authors listed] Early photocoagulation for diabetic retinopathy ETDRS report number 9. Early Treatment Diabetic Retinopathy Study Research Group. Ophthalmology. 1991;98(5):766-785. 
5. Mitchell P, Bandello F, Schmidt-Erfurth U, et al. The RESTORE study: ranibizumab monotherapy or combined with laser versus laser monotherapy for diabetic macular edema. Ophthalmology. 2011;18(4): 615-625.

6. Heier JS, Korobelnik JF, Brown DM, et al. Intravitreal aflibercept for diabetic macular edema: 148-week results from the VISTA and VIVID studies. Ophthalmology. 2016;123(11):2376-2385.

7. Gonzalez VH, Campbell J, Holekamp NM, et al. Early and long-term responses to anti-vascular endothelial growth factor therapy in diabetic macular edema: analysis of protocol I data. Am J Ophthalmol. 2016; 172:72-79.

8. Bressler SB, Ayala AR, Bressler NM, et al. Persistent macular thickening after ranibizumab treatment for diabetic macular edema with vision impairment. JAMA Ophthalmol. 2016;134(3):278-285.

9. Beck RW, Edwards AR, Aiello LP, et al. Three-year follow-up of a randomized trial comparing focal/grid photocoagulation and intravitreal triamcinolone for diabetic macular edema. Arch Ophthalmol. 2009; 127(3):245-251

10. Pacella E, La Torre G, Turchetti P, et al. Evaluation of efficacy dexamethasone intravitreal implant compared to treatment with anti-VEGF in the treatment of diabetic macular edema. Senses Sci. 2014;1(4): 164-168.

11. Boyer DS, Yoon YH, Belfort R Jr, et al. Three-year, randomized, shamcontrolled trial of dexamethasone intravitreal implant in patients with diabetic macular edema. Ophthalmology. 2014;121(10):1904-1914.

12. Callanan DG, Gupta S, Boyer DS, et al. Dexamethasone intravitreal implant in combination with laser photocoagulation for the treatment of diffuse diabetic macular edema. Ophthalmology. 2013;120(9): 1843-1851.

13. Mathew R, Pearce E, Muniraju R, Abdel-Hay A, Sivaprasad S. Monthly OCT monitoring of Ozurdex for macular oedema related to retinal vascular diseases: re-treatment strategy (OCTOME Report 1). Eye. 2014;28(3):318-326.

14. Gillies MC, Lim LL, Campain A, et al. A randomized clinical trial of intravitreal bevacizumab versus intravitreal dexamethasone for diabetic macular edema: the BEVORDEX study. Ophthalmology. 2014;121(12):2473-2481.

15. Goñi FJ, Stalmans I, Denis P, et al. Elevated intraocular pressure after intravitreal steroid injection in diabetic macular edema: monitoring and management. Ophthalmol Ther. 2016;5(1):47-61.

16. Ramu J, Yang Y, Menon G, et al. A randomized clinical trial comparing fixed vs pro-re-nata dosing of Ozurdex in refractory diabetic macular oedema (OZDRY study). Eye. 2015;29(12):1603-1612.

17. Mangione CM, Lee PP, Gutierrez PR, et al. Development of the 25-item National Eye Institute Visual Function Questionnaire. Arch Ophthalmol. 2001;119(7):1050-1058.
18. Mangione CM, Lee PP, Pitts J, Gutierrez P, Berry S, Hays RD. Psychometric properties of the National Eye Institute Visual Function Questionnaire (NEI-VFQ). NEI-VFQ Field Test Investigators. Arch Ophthalmol. 1998;116(11):1496-1504.

19. Brose LS, Bradley C. Psychometric development of the individualized Retinopathy-Dependent Quality of Life Questionnaire (RetDQoL). Value Health. 2010;13(1):119-127.

20. Brose LS, Bradley C. Psychometric development of the Retinopathy Treatment Satisfaction Questionnaire (RetTSQ). Psychol Health Med. 2009;14(6):740-754.

21. Pacella F, Romano MR, Turchetti P, et al. An eighteen-month follow-up study on the effects of Intravitreal Dexamethasone Implant in diabetic macular edema refractory to anti-VEGF therapy. Int $J$ Ophthalmol. 2016;9(10):1427-1432.

22. Pacella F, Ferraresi AF, Turchetti P, et al. Intravitreal injection of Ozurdex(®) implant in patients with persistent diabetic macular edema, with six-month follow-up. Ophthalmol Eye Dis. 2016;8:11-16.

23. Pacella E, Vestri AR, Muscella R, et al. Preliminary results of an intravitreal dexamethasone implant (Ozurdex $®$ ) in patients with persistent diabetic macular edema. Clin Ophthalmol. 2013;7:1423-1428.

24. Malclès A, Dot C, Voirin N, et al. Real-life study in diabetic macular edema treated with dexamethasone implant: The Reldex Study. Retina. Epub 2016 Jul 28.

25. Milne A, Johnson JA, Tennant M, Rudnisky C, Dryden DM. Measuring Health-Related Quality of Life for Patients with Diabetic Retinopathy. Rockville, MD: Agency for Healthcare Research and Quality (US); 2012.

26. Okamoto Y, Okamoto F, Hiraoka T, Oshika T. Vision-related quality of life and visual function following intravitreal bevacizumab injection for persistent diabetic macular edema after vitrectomy. Jpn J Ophthalmol. 2014;58(4):369-374.

27. Suñer IJ, Kokame GT, Yu E, Ward J, Dolan C, Bressler NM. Responsiveness of NEI VFQ-25 to changes in visual acuity in neovascular AMD: validation studies from two phase 3 clinical trials. Invest Ophthalmol Vis Sci. 2009;50(8):3629-3635.

28. Alagöz N, Alagöz C, Y1lmaz I, et al. Immediate intraocular pressure changes following intravitreal dexamethasone implant. $J$ Ocul Pharmacol Ther. 2016;32(1):44-49.

29. Pacella F, Agostinelli E, Carlesimo SC, et al. Management of anterior chamber dislocation of a dexamethasone intravitreal implant: a case report. J Med Case Rep. 2016;10(1):282.
Patient Preference and Adherence

\section{Publish your work in this journal}

Patient Preference and Adherence is an international, peer-reviewed, open access journal that focuses on the growing importance of patient preference and adherence throughout the therapeutic continuum. Patient satisfaction, acceptability, quality of life, compliance, persistence and their role in developing new therapeutic modalities and compounds to optimize

\section{Dovepress}

clinical outcomes for existing disease states are major areas of interest for the journal. This journal has been accepted for indexing on PubMed Central. The manuscript management system is completely online and includes a very quick and fair peer-review system, which is all easy to use. Visit http://www. dovepress.com/testimonials.php to read real quotes from published authors. 